\title{
Uma construção luminosa: o cinema e a Exposição Internacional de 1937
}

\author{
A luminous construction: \\ the cinema and the World Fair of 1937
}

Eduardo Victorio Morettin

Uma exposição internacional é um confronto. Edmond Labbé, comissário geral da Exposition Internationale des Arts et Techniques dans la Vie Moderne (1937)

As relações entre história e cinema podem ser examinadas tomando-se diferentes pontos de partida, sempre conexos. $\mathrm{O}$ exame que considera a análise interna dos filmes privilegia sua dimensão como fonte histórica na medida em que consegue avaliar a efetiva contribuição que a articulação entre imagens e sons propõe a respeito de determinado tema ou época. Constitui outro caminho

Eduardo Victorio Morettin é professor de História do Audiovisual do Departamento de Cinema, Rádio e TV da Escola de Comunicações e Artes e coordenador do Programa de Pós-Graduação em Meios e Processos Audiovisuais da Universidade de São Paulo (USP), Brasil (cunhamorettin@uol.com.br).

Artigo recebido em 30 de dezembro de 2012 e aprovado para publicação em 20 de março de 2013.

Est. Hist., Rio de Faneiro, vol. 26, no 51, p. 73-93, janeiro-junho de 2013. 
entender o cinema como fenômeno de expressão de um conjunto de valores sociais dentro de um quadro mais amplo vinculado tanto à história cultural quanto à história do próprio meio de comunicação de massa. Tal compreensão, contudo, que deve ser pensada como um processo que não se resume à identificação de filmes e de diretores ou à apresentação de um contexto tomado apenas como pano de fundo.

A proposta deste artigo é discorrer sobre este último campo, tomando como objeto de análise a participação do cinema na Exposition Internationale des Arts et Techniques dans la Vie Moderne, realizada em Paris em 1937, discutindo assim as imbricações entre a cultura da modernidade e as contendas políticas e ideológicas no período entre guerras.

O cinematógrafo, invenção do final do XIX, participou desde seu início de uma história já pregressa, a saber, a das exposições internacionais, espaços de celebração do capitalismo e de seus avanços, que teve na The Great Exhibition of the Works of Industry of all Nations, realizada em Londres em 1851, sua primeira edição. Síntese do avanço científico, pela inovação tecnológica que representava, e do artístico, dado o lugar que ocupava desde a década de 1910 nos debates estéticos, o cinema foi tomado simbolicamente por diferentes países como indício de que o domínio econômico encontrava correspondência em uma trajetória vinculada ao desenvolvimento cultural. Filmes como Nascimento de uma nação (1915), de David Griffith, ou Metropolis (1927), de Fritz Lang, atestam essa tendência (Xavier, 1999).

De início tímida ou circunstancial, essa participação se intensificou à medida que o cinema, nas décadas de 1920 e 1930, se institucionalizou e se consolidou como meio de comunicação de massa (Morettin, 2011). Objeto de políticas públicas por parte de governos, autoritários ou não, interessados em conquistar simbolicamente um número maior de pessoas para sua causa, e cada vez mais utilizado como um dos elementos de confronto entre as nações, para recuperarmos a expressão de Edmond Labbé, o cinema atravessou a Exposição de 1937, participando de forma mais incisiva nas disputas simbólicas de um mundo prestes a entrar em seu segundo conflito mundial. Atingindo um público maciço e constituindo-se na principal 'vitrine' em que a nação projetava as virtudes a serem comemoradas, seriam várias as iniciativas dedicadas ao cinema, ações que não se restringiriam apenas ao espaço expositivo, como veremos.

A Exposition Internationale des Arts et Techniques dans la Vie Moderne realizada em Paris entre maio e novembro de 1937, em meio à Guerra Civil Espanhola e à consolidação do nazifascismo, e dois anos antes da eclosão da Segunda Guerra, foi, segundo Lemoine (1987: 13), a sétima e última exposição desse tipo em Paris e na França. ${ }^{1}$ De acordo com Marc Mancini (1983: 44), foi nessa exposição "que tanto o escopo quanto a seriedade atingi- 
dos pelo exhibition film se tornaram evidentes". Trata-se agora de apresentar tal evidência, avaliando a participação do cinema, sua capacidade de mobilização e sua potência como catalisador do sentido mais profundo de um mundo prestes a cair em um abismo.

\section{A Frente Popular: socialismo e exposição universal}

Como acontece praticamente em todas as exposições, o período entre a idealização e a concretização da Exposição de 1937 foi longo, repleto de atrasos e tomado por dúvidas em relação à sua viabilidade(Lemoine, 1987: 13 e ss; Labbé, t. I, 1938: 34 e ss). No decorrer de seus preparativos, marcado por greves, falta de materiais e ampliação da área, em julho de 1936 assumiu o governo da França a Frente Popular, que imprimiu nova orientação ao evento, mais coerente com a perspectiva das forças da esquerda que agora se encontravam no poder. Entre as iniciativas que ganharam corpo com a Frente Popular estiveram: a celebração da vida operária e campesina, expressa com o Centre Rural, a Maison du Travail e o Pavilhão da Solidariedade; as festas populares, como a Festa do Trabalho, confiadas pela organização às associações culturais de esquerda; a política de popularização da Exposição; e o empenho na difusão do conhecimento e na vulgarização científica, sendo a exposição Chefs d'Oeuvre de l'Art Français e o Palais de la Découverte dois exemplos nesse sentido. Esse espaço expositivo, idealizado para ser temporário, permaneceu em razão de seu sucesso. A grande frequência de público à Exposição Internacional foi celebrada pela esquerda como sua vitória política. $^{2}$

A motivação econômica da Exposição era clara. Dada a crise de 1929, os objetivos eram a recuperação da indústria e do artesanato nacionais, além da diminuição do desemprego, alto entre os artistas.

Do ponto de vista ideológico, duas eram as intenções. A primeira, celebrar a paz mundial. ${ }^{3}$ Um filme emblemático desse desejo, que não era restrito aos organizadores da Exposição, foi $A$ grande ilusão (1937), de Jean Renoir, artista afinado com a política da Frente Popular. Apesar de não ter participado diretamente do evento, a obra foi lançada nas salas do circuito comercial durante a Exposição, com enorme acolhida de crítica e de público. É importante recuperar uma crônica escrita pelo diretor para o jornal Ce Soir em 22 de julho de 1937, artigo que parece fazer coro ao sentido mais geral do filme. Renoir conta que dois turistas alemães foram hostilizados dentro da Exposição por uma francesa pelo fato de ela supor que se tratava de nazistas. Ela teria agido segundo o seguinte raciocínio: "se os nazistas eram de origem germânica, a recíproca deveria ser verdadeira”. A partir desse incidente, o cineasta conclui que em França todos deveriam 
tratar bem, tanto do ponto de vista material como moral, os estrangeiros que visitassem a Exposição. Em relação ao último ponto, seria um ganho para a democracia se os alemães voltassem a seu país imbuídos não apenas do espírito de liberdade que predominava nas instituições oficiais, mas daquele "que vinha da amabilidade, da brandura dos costumes, da ausência de preconceitos da população". Por isso se explica o título de seu pequeno artigo: "A Exposição da Liberdade" (Renoir, 1937).

A segunda intenção era "contribuir para a cooperação intelectual da humanidade". Essa perspectiva seria materializada por meio de uma exposição dedicada ao Pensamento, dado que o tricentenário do Discurso do método de Descartes também estava sendo celebrado naquele ano, e dezenas de congressos estavam sendo realizados (Lemoine, 1987: 14).

\section{Arte e técnica: o ecletismo e o lugar do modernismo}

O tema da Exposição de 1937, como seu próprio título indica, foi a conjunção entre arte e técnica, o que lhe conferiu um recorte mais específico se comparada às anteriores. De acordo com Edmond Labbé (t. I, 1938: 56), seu objetivo era reunir

as obras originais dos artistas e dos industriais. Ela se esforçará por mostrar que as realizações artísticas podem intervir nos domínios os mais modestos, que nenhuma incompatibilidade existe entre o belo e o útil, que a arte e as técnicas devem ser indissoluvelmente ligadas, que se o progresso natural se desenvolve sob o signo da arte, ele favorece o florescimento dos valores espirituais, patrimônio superior da humanidade. Ela será aberta a todas as produções que apresentarem uma característica indiscutível de arte e de novidade.

Essa valorização do belo e do útil, como se entendia a ligação entre os dois campos, podia ser percebida na Exposição pela presença dos "métiers d'art, orientados na direção dos objetos de luxo", do "artesanato ligado a uma produção essencialmente regional" ou da "arte a serviço da indústria" (Lemoine, 1987: 15).

Essa orientação geral tinha como resultado a falta de uma concepção artística única, sendo a marca da Exposição o ecletismo. A ausência de um estilo predominante residia, entre outros aspectos, no objetivo declarado de dar emprego ao maior número de artistas possível. Ao final, 464 artistas plásticos, 271 escultores e 269 artistes décorateurs receberam algum tipo de encomenda, sem que 
houvesse a expectativa de que todos os trabalhos fossem obras-primas, como disse o diretor dos trabalhos de arte, Louis Hautecoeur, conservador do Musée de Luxembourg (apud Chavanne e Guttinger, 1987: 366).

Nesse quadro, a arte moderna também participou. De um lado, o próprio tema da Exposição, arte e técnica, era caro aos intelectuais preocupados com o realismo na França, como Louis Aragon. Em 1935 ele afirmava a necessidade de o escritor ser um "engenheiro das almas (um conceito que pode ser encontrado em Stalin), no sentido científico da palavra engenheiro" (apud Huhn, 1987: 394). Para os que defendiam uma perspectiva de realismo diferente, a Exposição era vista como lugar de experimentação do binômio velocidade e arte abstrata. Como disse um crítico na época, as pinturas murais de Robert e Sonia Delaunay, Léopold Survage e Félix Aublet, obras que se destacaram no evento, eram "vertigens do infinitamente pequeno e do infinitamente grande, jogos feéricos da difração e das interferências, foguetes e fusão, tudo não passa de uma ilusão, o tempo é somente sonho..." (Chéronnet, apud 1937, Exposition Internationale des Arts et des Techniques, 1979: 15). As pinturas murais, que também marcaram a Exposição, representaram o compromisso do artista de renunciar ao trabalho de pequenas proporções, destinado às coleções privadas, rumo à criação de um sentido coletivo a ser usufruído no espaço público. ${ }^{4}$

Léon Blum, dirigente da Section Française de l'Internationale Ouvrière (SFIO) e chefe de governo da Frente Popular, tomou duas decisões que foram consideradas pró-modernistas: a contratação dos Delaunay, Robert e Sonia, para a ornamentação do Pavillon de l'Air e a entrega do projeto do Pavillon des Temps Nouveaux ao grupo de Le Corbusier. Além disso, os modernistas foram chamados para compor os júris oficiais das diferentes exposições organizadas no campo das artes visuais, o que "permitia, pelo menos, situar dentro de uma lógica 'progressista' os programas artísticos dos espaços da Frente Popular na Exposição, que, sem eles, deixaria uma imagem ambígua” (Ory, 1987: 33).

Apesar dessas medidas oficiais, a participação dos artistas modernos nos pavilhões franceses era pequena. As comissões responsáveis pela seleção

preferiram respeitar todos os movimentos e distribuir os trabalhos proporcionalmente a cada grupo estilístico. É por isso que é falso reter da Exposição somente as criações de Delaunay, Aublet ou Léger, e difícil inferir um estilo ‘37’ (Chavanne e Guttinger, 1987: 367).

Em relação aos pavilhões estrangeiros, a situação era a mesma. Guernica (1937), de Pablo Picasso, feita especialmente para o pavilhão do governo republicano espanhol, outro emblema da Exposição, não foi a tônica. 


\section{O confronto arquitetural}

Um dos campos em que primeiro a propaganda tomou corpo foi o arquitetônico. A Exposição de 1937 se tornou conhecida pelo "dramático confronto arquitetural" entre dois pavilhões que foram posicionados um de frente para o outro: de um lado, o da União Soviética; de outro, o nazista, concebido por Albert Speer (Chandler, 1990: 286-288). Do ponto de vista arquitetônico, os dois pavilhões foram exemplares em sua vontade de expressar simbolicamente a força e o poder de cada Estado em luta que não demoraria muito para se tornar real.

O pavilhão soviético era marcado pelas ambiguidades trazidas pela introdução do realismo socialista nos anos 1930. Já o pavilhão nazista foi pensado como resposta ao comunista. Após ter visto a maquete do que seria o futuro pavilhão soviético, Albert Speer conta, em livro de 1971, o que resolveu fazer:

(...) eu concebi um cubo maciço, cadenciado por pesadas pilastras, dando a impressão de impedir um ataque, enquanto que, do alto da cornija de minha torre, uma águia, a suástica com suas garras, media de alto a baixo a dupla soviética (apud Lemoine, 1987: 19). ${ }^{5}$

O pavilhão nazista e o soviético frente à frente

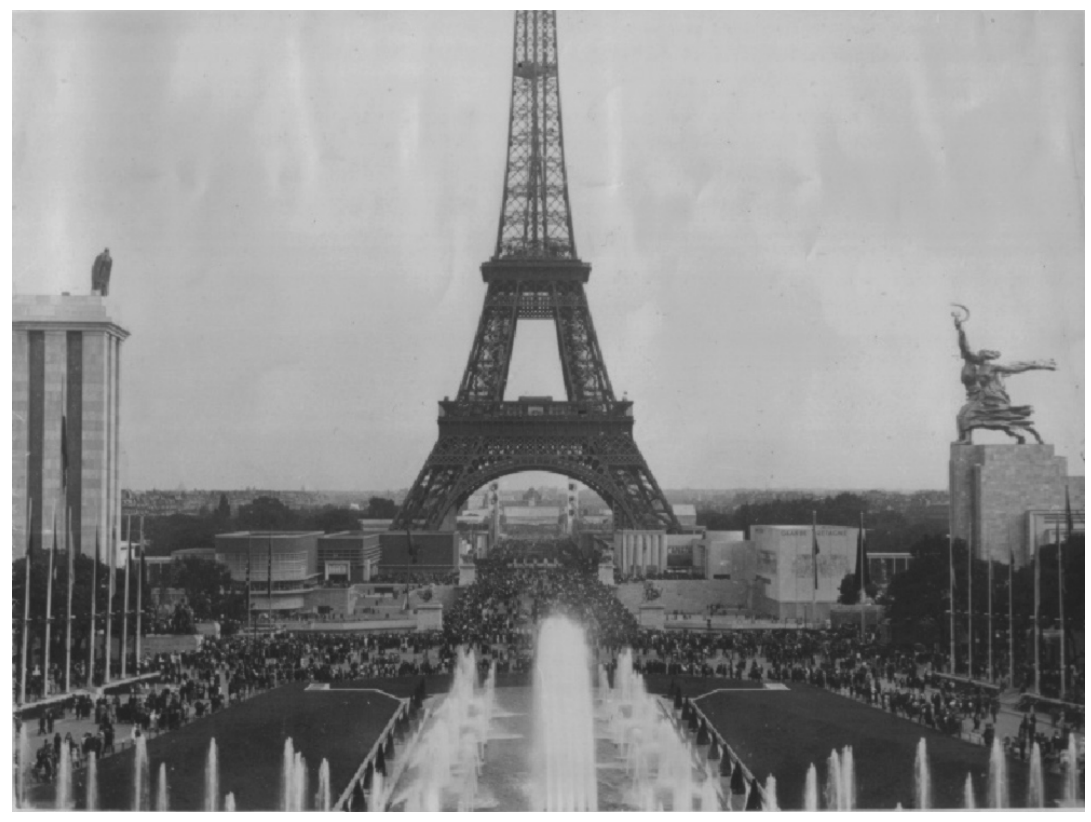


O pavilhão de Speer foi concebido como um 'santuário do Estado'. Santuário também no sentido de valorizar a morte e o sacrifício necessários à consolidação do Estado Nacional. Nesse sentido, tal é a leitura de Dieter Bartezko:

A torre frontal do pavilhão de 1937 é uma transcrição monumental e brutal desses templos, ou melhor, desses mausoléus. (...) ela manifesta o gosto pela morte do sistema nazista. A torre frontal aparece como um monumento funerário e o hall como um sarcófago megalômano (Bartezko, 1987: 137).

\section{O pavilhão alemão à noite}

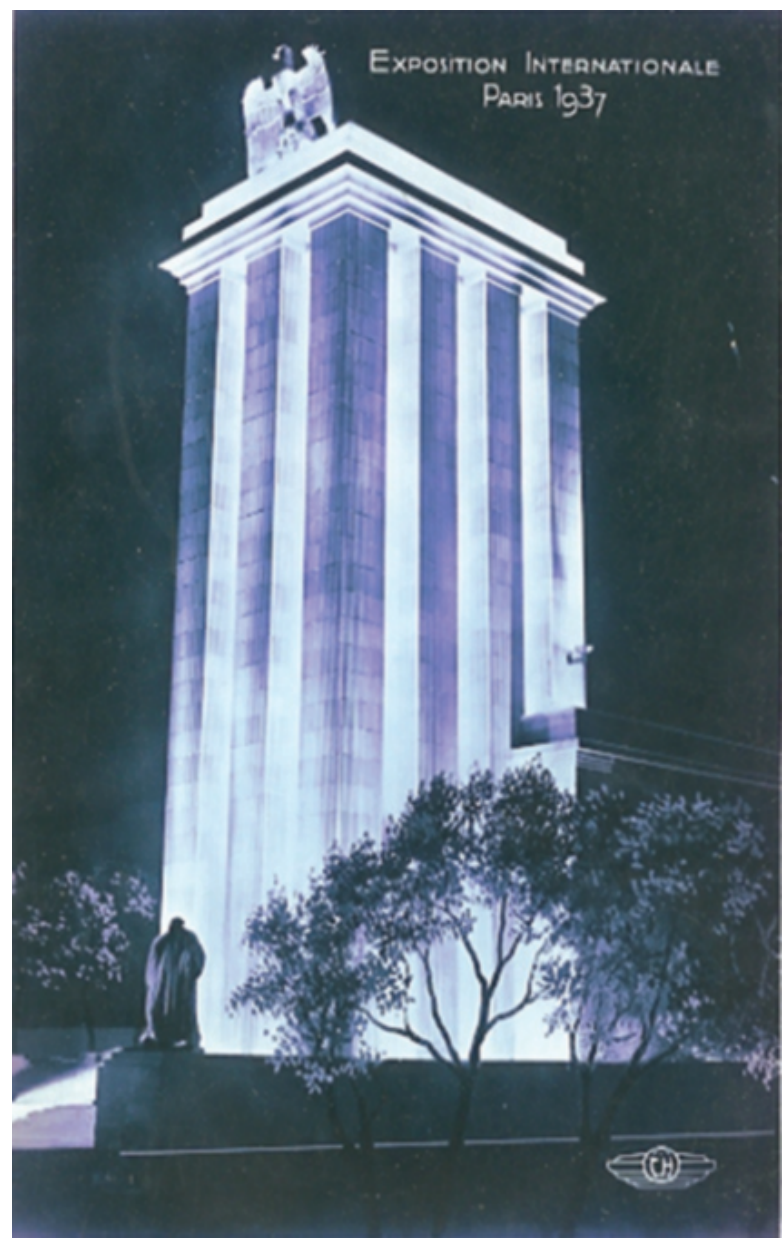


Para o autor, a construção sintetiza as principais características da arquitetura nazista, vista como "uma demonstração diante da opinião internacional do renascimento da nação":

Seus materiais: as formas neoclássicas; seu objetivo: o fascínio das massas; seu procedimento mais importante: a luz, símbolo da separação entre o bem e o mal, criadora de uma atmosfera mágica, encarnação da pureza. Cada realização da arte nazista era cercada de projetores e se tornava à noite uma construção luminosa (Bartezko, 1987: 135 e 138$){ }^{6}$

Como diz Bartezko, a propósito desse cenário, “é apenas no halo dos projetores e dos candelabros que se completa essa arquitetura, testemunho ilusório daquilo em que os nazistas do Terceiro Reich acreditavam" (Bartezko, 1987: $139){ }^{7}$

Essa 'arquitetura cristalina' e luminosa, como bem observou Bartezko, também estava presente nos filmes de montanha de Leni Riefensthal e naqueles em que a arquitetura desempenha papel fundamental, como o Triunfo da vontade (1935), filme exibido na Exposição de 1937.

\section{O cinema como expressão do Pensamento: concursos, pavilhão e propaganda}

A grande estrela da Exposição, vetor e símbolo da modernidade a ser celebrado, foi a eletricidade. Um pavilhão a ela dedicado, o da Eletricidade e da Luz, concebido por Robert Mallet-Stevens e Georges Pingusson, além de pinturas murais, como as de Raoul Dufy e Léger, e festas noturnas acompanhadas por músicas compostas por Darius Milhaud, Georges Auric, Arthur Honegger, Jacques Ibert, contribuíram para dar forma a esse etéreo elemento.

$\mathrm{O}$ cinema era onipresente, meio de comunicação que sintetizava arte e técnica. Como dissemos, a celebração da eletricidade e da luz pela Exposição, bem como a valorização da 'arquitetura cristalina' em diferentes pavilhões, principalmente o nazista, potencializavam o cinema como expressão por excelência da pretendida modernidade. Sinal dessa expressão foi a construção de uma tela gigante, na fachada do Pavilhão da Eletricidade e da Luz, para a projeção de filmes panorâmicos feitos especialmente para a ocasião (Lemoine e Rivoirard, 1987: 221-233).

O próprio programa da Exposição, estabelecido em novembro de 1934, nivelou, pelo alto, o lugar do cinema. Ele estava no Grupo I, 'Expression de la 
pensée', classe 6, 'Manifestations cinématographiques', grupo que foi presidido por Paul Valéry (Labbé, t. I, 1938: 301). ${ }^{8}$ Tratava-se de um reconhecimento efetivo por parte das autoridades do lugar ocupado pelo cinema na cultura contemporânea. Não mais um anexo ou um auxiliar da imprensa ou da fotografia, como na Exposição Universal de Paris de 1900 (Morettin, 2011: 233-234), mas um meio autônomo de expressão do pensamento. Como diz Labbé,

o cinematógrafo reina de maneira incontestável sobre todos os pontos do globo. (...) Sua influência, seu poder, a eloquência precisa das imagens animadas que ele surpreende e registra em todo o universo fazem dele o melhor dos diplomatas, dos repórteres, dos advogados, dos agentes de propaganda. (...) Ele informa e ensina (t. V, 1939: $60)$.

Esse discurso era recorrente na época, sendo o cinema valorizado pelo seu poder de convencimento e pela sua capacidade de rapidamente transmitir as informações necessárias.

A classe 6 , cuja presidência de honra cabia a Louis Lumière, ${ }^{9}$ tinha por missão

demonstrar que o cinema é um dos mais preciosos auxiliares do Pensamento! O cinema deveria (...) colaborar para a magia da Exposição e acrescentar ao seu espetáculo. (...) Ele deveria ser, em uma palavra, uma das expressões mais completas desta vida moderna que a nossa Exposição tenciona mostrar sob os seus aspectos os mais diversos e mais brilhantes (Labbé, t. V, 1939: 61).

Coube à comissão dirigente da classe 6 promover vários concursos em outubro de 1937 a fim de escolher o melhor filme: de ficção francês; documentário ou de reportagem; de amadores "(formatos reduzidos) franceses ou estrangeiros"; científico, e, "entre os filmes técnicos, [aqueles] que possam contribuir para o desenvolvimento da Arte cinematográfica” (Labbé, t. V, 1939: 62).

O processo relativo ao concurso para os filmes de ficção traz alguns elementos para pensarmos o ideal de cinema que a comissão defendia. Doze longas se inscreveram no Grand Prix des Films Français présentés au jury de l'exposition, ${ }^{10}$ mas apenas seis participaram (Labbé, t. V, 1939: 63). No relatório das classes 6 e 14, a justificativa para que La Bataille Silencieuse, de Pierre Bilan, Drôle de Drame, de Marcel Carné, Forfaiture e La Citadelle du Silence, ambos de Marcel 
L'Herbier, e Le Messager, de Raymond Rouleau, fossem descartados da competição foi "que eles não preenchiam todas as condições fixadas pelo regulamento" (Cerf, 1937: 43). ${ }^{11}$

De todos os filmes não classificados, o exame mais detalhado de Forfaiture (1937), de Marcel L'Herbier, nos fornece algumas pistas para uma melhor compreensão do regulamento. O filme é uma homenagem a The Cheat (1915), de Cecil B. de Mille, como indicado logo em sua apresentação, quando imagens da obra de 1915 e um letreiro deixam claro o tributo. Na França, The Cheat foi lançado como Forfaiture, e seu impacto foi enorme, como a tardia homenagem de L'Herbier indica. ${ }^{12} \mathrm{Um}$ dos motivos de seu reconhecimento se deveu à atuação de Sessue Hayakawa, que interpretava o vilão, papel que lhe conferiu no cinema silencioso americano grande notoriedade. Hayakawa morava à época em Paris e foi escalado por L'Herbier para interpretar a mesma personagem na refilmagem de The Cheat.

Há, porem, mudanças na história. Na adaptação francesa, o drama se passa na Mongólia, situando o filme na questão colonial, já que acompanharemos o que se passará com Pierre, responsável pela construção de uma estrada na região, financiada com capital francês oriundo da Société Franco-Mongole. A primeira imagem do filme é a da chegada de Denise, sua mulher, a uma estação perdida em meio ao deserto. Ela é levada por um motorista em seu caminhão ao acampamento onde Pierre a espera. O caminhão transporta também trabalhadores, todos eles marcados a ferro e a fogo nas costas, marca feita pelo príncipe e grande proprietário de minas da região, interpretado, como veremos a seguir, por Hayakawa. A tensão, não percebida por Denise, transparece no rosto do motorista, e a justificativa vem a seguir. O comboio é alvo de um tiroteio, mas todos conseguem escapar. Inesperadamente, surge na estrada uma limusine. O motorista conversa com o chofer, e uma carona é oferecida a Denise. Dentro do carro, ela tem o seu primeiro encontro com o príncipe Hu-Long. Seu desejo por Denise é patente. Ela, por sua vez, se não chega a corresponder, demonstra por ele grande curiosidade. Dentro do carro, ela percebe também que o homem ao seu lado é o príncipe, 'dono' dos camponeses.

Pierre sofre com as dificuldades para o término da obra, como o tiroteio indica. Certo de que o mandatário local está por trás dos problemas, solicita uma reunião. Pierre somente é recebido por Hu-Long quando este é informado de que Denise é sua mulher. Começa, então, o jogo que enredará os dois na teia armada pelo vilão.

Como todo vilão, ele não é transparente em suas ações: promete a Pierre que os ataques cessarão, o que não cumpre, contribuindo para o aumento das tensões no acampamento; e introduz Denise no jogo de azar que é disputado em um clube da cidade, jogo que provocará a ruína financeira de Denise, vício e que- 
da que também dizem muito sobre ela. No caminho da perdição, Denise rouba o que havia sido arrecadado em uma festa organizada pela Cruz Vermelha a fim de pagar sua dívida no jogo e, a fim de não cair em desgraça, pede dinheiro emprestado ao príncipe, que, como se imagina, cobrará a dívida mais tarde. Acuada, Denise sabe que está enredada e, ao contar sua história à mulher do embaixador inglês, conclui: "Eu estou perdida".

Pierre é chamado a Paris pelos societários. De um lado, não consegue finalizar a obra. De outro, cartas enviadas da Mongólia sugerem que o responsável pela construção da estrada estaria desviando recursos da empresa para sustentar o estilo de vida de sua mulher. Quando Pierre chega à reunião, é informado de um relatório contrário à sua gestão. $\mathrm{O}$ documento fora preparado pelo príncipe, que se encontra também em Paris a fim de trabalhar pela sua demissão, dado que seu objetivo é eliminá-lo a fim de possuir sua mulher.

Pierre, ao invadir a casa de Hu-Long para cobrar dele satisfações, depara-se com o príncipe agonizando. Ao vê-lo no chão, segura a arma do crime e é surpreendido por um dos assistentes do príncipe. O cenário está montado: sabemos que ele não foi o autor do tiro, e o suspense criado é direcionado no sentido de descobrirmos a identidade do verdadeiro assassino.

Nós sabemos que Pierre é inocente, mas não as personagens da história. Por isso, ele é preso e levado a julgamento. Tudo o que havia sido escondido dele vem à tona naquele momento 'público', autêntico drama de tribunal. No decorrer do processo, Denise é incriminada. Diante da descrença do marido e da iminência de sua condenação, ela resolve confessar o assassinato, momento do flash back final de Forfaiture: Denise se encontra com Hu-Long, pedindo a ele que pare com as sabotagens e engavete o relatório feito contra o marido; o príncipe entende ser a hora de cobrar sua dívida; eles discutem e se agridem fisicamente; subjugada, Denise é posta de bruços sobre uma mesa, tem o vestido rasgado, e o príncipe consegue marcá-la nas costas, como fez com seus trabalhadores; após ser 'possuída', ela se desvencilha, toma um revolver que se encontrava na cena, e efetua os disparos.

Voltamos ao tribunal, e o procurador, não satisfeito apenas com a confissão, pede uma prova. Diante de todos, ela se desnuda para mostrar em suas costas a marca do príncipe. Por mais que ao final tenhamos a conciliação entre Pierre e Denise (o marido acredita naquilo que sua mulher lhe confidencia - "Eu estava louca, mas eu não te enganei"), o filme, em seu conjunto, destoa completamente do tom pretendido pela Exposição. Não há a celebração da virtude e do progresso. A questão colonial é tomada como pano de fundo para uma história com moral ambígua: apesar do assassinato do vilão, sua marca no corpo da mulher é permanente; Denise tem conduta questionável, e a atração entre ela e o príncipe é trabalhada de forma a deixar dúvidas no espectador. Por isso, é o próprio filme que traz os motivos de sua desclassificação do concurso. 
Por outro lado, assistindo a Les perles de la couronne (1937), de Sacha Guitry, entendemos também os motivos de sua seleção. Ao contar, com toda sua verve dramática e domínio de cena, a história sobre a origem das quatro pérolas que ornavam a coroa da Inglaterra, Guitry passeia por diferentes momentos da história da Europa, motivo para que sejam encenadas situações ligadas às cortes europeias, como a de Catarina de Médicis, de Henrique VIII, de Maria Stuart e assim por diante. Como as pérolas passam de mão em mão e de geração a geração, chegamos ao presente e à investigação sobre seu destino. As sequências finais se passam dentro do navio Normandie, sendo o último plano uma imagem aérea do navio. A embarcação, inaugurada em 1935, era tratada como orgulho nacional, e sua decoração interna, que vemos em alguns planos, foi "a última marca desta empresa Art déco" (Bréon, 2006: 16-17). Luxo na reconstituição histórica, atuação de uma figura respeitada no mundo teatral, preocupação com o vernáculo culto e sintonia com os símbolos da modernidade de sua época também nos auxiliam a compreender os motivos de sua inclusão no concurso.

Além desse concurso, o comissário geral da Exposição, por intermédio do ministro des Affaires Étrangères, pediu que cada país "reconhecidamente produtor de filmes" indicasse uma obra para apresentá-la em Paris durante uma das seis grandes festas organizadas pela classe. Além disso, cada país enviou um filme considerado significativo de seus avanços no campo cinematográfico. Noites de gala foram organizadas pela comissão em homenagem à indústria cinematográfica inglesa, tchecoslovaca, japonesa, alemã, soviética e francesa (Labbé, t. V, 1939: 62 e 64).

A fim de materializar a dimensão adquirida pelo cinema no evento foi construído, pela primeira vez em uma exposição universal, um pavilhão dedicado à cinematografia, à fotografia e ao som. Embaixo da Torre Eiffel, o Pavilhão Photo-Ciné-Phono ${ }^{13}$ respondeu às demandas já existentes desde a Exposition Internationale des Arts Décoratifs et Industriels Modernes de 1925 por um espaço expositivo maior.

No que diz respeito à parte que cabia à cinematografia, localizada no piso superior do pavilhão, o objetivo era abordar o processo, da fabricação da película à sala de exibição. Sons os mais variados (fragmentos de músicas, solilóquio de Sacha Guitry etc.) ocupavam os ambientes. Três exposições foram dedicadas: ao cinema educativo; ao cinema amador; e às "aplicações diversas do cinema". Uma vasta sala "foi arrumada para os stands da indústria cinematográfica". Uma ala foi consagrada às "aplicações científicas do cinema, aos noticiários cinematográficos e à federação de clubes de cinema amadores". Pinturas ornamentavam as salas, os corredores e os halls, tendo por tema os assuntos abordados, como o cinema recreativo, o cinema instrutivo etc. (Labbé, t. V, 1939: 248-251). 
Seu destaque era o Ciné 37, sala de exibição de 1.200 lugares. No discurso feito pelo comissário geral, Edmond Labbé, por ocasião da colocação da primeira pedra do pavilhão, o cinema era tomado como a "potência ditatorial da época" (apud Peer, 1987: 234-236). Além das sessões de gala dedicadas a celebrar a cinematografia de cada país, quatro horas de programação diárias ocuparam seu espaço do dia 29 de junho até o dia 25 de novembro de 1937. Treze países ocuparam com regularidade as sessões do Ciné 37: Alemanha, Áustria, Finlândia, França, Grã-Bretanha, Itália, Japão, Luxemburgo, Polônia, Romênia, Tchecoslováquia, África do Sul e URSS (Labbé, t. V, 1939: 65-66).

Afora esse grande cinema, os pavilhões e demais edificações contavam com 40 salas de exibição. O jornal diário Programme Quotidien Officiel de l'Exposition Internationale des Arts et Techniques, que noticiava as principais atrações, trazia a programação dos cinemas dos pavilhões estrangeiros (Dinamarca, Alemanha, URSS, Países Baixos, Suíça, Bélgica, Tchecoslováquia, Espanha, Hungria) e de pavilhões específicos, como o da Lumière, o Centre Rural, o Palais des Chemins de Fer, e, eventualmente, do Ciné 37.

No que diz respeito às atividades de divulgação da própria Exposição, sua propaganda pelo cinema era vista como estratégica, e o relatório sobre essa atividade é um dos mais densos se comparado com o das exposições anteriores (Morettin, 2011). A função do cinema era "provocar, pela magia das imagens vivas e dos textos dinâmicos, a curiosidade intelectual do mundo inteiro em torno do gigantesco empreendimento" e "estimular o sentimento de fraternidade universal que solicitava" um evento daquela magnitude (Labbé, t. XI, 1940: 295).

Atingir um público amplo era uma das metas pretendidas ao se recorrer ao cinema. De um lado, isso foi realizado por meio de um vasto programa de curtas-metragens, atualidades e documentários "de propaganda propriamente ditos, que o Comissariado Geral devia especialmente encomendar”. Labbé detalha o programa adotado para a confecção de curtas-metragens, os acordos feitos com as empresas de atualidades cinematográficas que atuavam nesse setor etc. (Labbé, t. XI, 1940: 296-300).

Dentro desse programa, deve ser salientada a iniciativa de Pierre Mortier, diretor geral do Serviço de Propaganda a partir de dezembro de 1936 e comissário geral adjunto, que acordou com a Metro-Goldwin-Mayer a feitura de um filme de propaganda que foi exibido "nos cinemas do mundo inteiro" (Labbé, t. XI, 1940: 13).

A MGM organizou um concurso, aberto a 19 países, em que os concorrentes deveriam "descrever, o mais claramente possível, 'o que Paris representa a seus olhos"”. Os vencedores "desse jogo literário" teriam como prêmio uma viagem gratuita à Exposição, com estadia de duas semanas em Paris. Seriam agra- 
ciados 32 candidatos, divididos por região. Ao Brasil cabia uma vaga (Labbé, t. XI, 1940: 301).

$\mathrm{O}$ atrativo, porém, não se restringia à viagem e à oportunidade de conhecer Paris. A MGM

se reservava o direito de utilizar, para a confecção de um roteiro ou para elementos de um documentário, as ideias descobertas nas respostas e suscetíveis de serem aproveitadas em um filme dedicado à glória de Paris, de modo que alguns laureados poderiam ganhar não somente uma viagem e estadia gratuitas em Paris, mas ainda os direitos de autor! (Labbé, t. XI, 1940: 302).

Para lançar a campanha, a empresa norte-americana realizou um filme de propaganda com imagens de Paris, que foi exibido em abril de 1937 em todas as salas de cinema da companhia, como complemento que acompanhava Camille (1936), de George Cukor, adaptação de La Dame aux Camélias, com Greta Garbo no papel principal (Labbé, t. XI, 1940: 302). A iniciativa foi muito elogiada pelo comissário geral, pois "contribuiu fortemente para estimular o interesse da opinião pública mundial em favor da grandiosa manifestação para a qual Paris convidou o universo" (Labbé, t. XI, 1940: 303).

O filme de propaganda foi exibido a 7 de maio de 1937 para as autoridades da Exposição.

De acordo com o relatório oficial, 16,354 milhões de espectadores viram o filme em 2.156 salas espalhadas pelo mundo. Há dados por país: no Brasil, teriam sido 312 mil em 37 salas; nos EUA, 7 milhões e 800 mil (Labbé, t. XI, 1940: 303).

Em relação ao concurso, tivemos 753.560 can didaturas no total, número que impressiona ainda hoje. Por país, foram aproximadamente 311 mil, EUA e Canadá; 160 mil, Inglaterra; 51 mil, Brasil; 46 mil, Itália; 45 mil, Argentina; 21 mil, Romênia; 19 mil, Polônia; 12 mil, Áustria; 12 mil, Alemanha; e assim por diante (Labbé, t. XI, 1940: 304). O Brasil, como se vê, aparece em quarto lugar no ranking, dado que atesta tanto a penetração do cinema americano em nosso país quanto o lugar que Paris e, portanto, a França ocupavam simbolicamente como aspiração para amplas parcelas da população.

Essa associação à MGM, concretizada já com a Frente Popular no governo, é reveladora de que o ecletismo acima apontado em relação às artes visuais era também predominante no caso do cinema. 


\section{O confronto entre as cinematografias no interior da Exposição}

Afora o ecletismo e a diversidade de manifestações ligadas ao campo cinematográfico, a dimensão de confronto, tão inerente a um evento como o das Exposições Universais, ganhou novo contorno por intermédio dos pavilhões. Vários tinham ou sala de cinema ou, como vimos, reservavam o espaço do Ciné 37 a fim de celebrar sua cinematografia. ${ }^{14} \mathrm{O}$ pavilhão soviético, por exemplo, tinha do lado de fora "uma sala de cinema completa" (Lambert, 1937).

No que diz respeito à Alemanha, a intenção das autoridades nazistas era garantir no evento uma presença significativa do cinema, arte-síntese da velocidade, vitalidade, energia e monumentalidade, elementos dispostos por seu pavilhão em diferentes objetos e stands. O pavilhão tinha, entre outras atrações, "no andar inferior, o escritório de informações, a sala de cinema e um grupo de cabines de televisão" (Lambert, 1937). Na sala do pavilhão, exibições diárias de filmes ocorreram desde o dia de sua inauguração, 6 de maio, até o fim da Exposição, no dia 25 de novembro, com a projeção de atualidades, filmes científicos e educativos, documentários e filmes de ficção. No Ciné 37, a programação era composta de filmes 'artísticos' alemães, exibidos três vezes por semana, "especialmente em noites dedicadas aos filmes de ficção e noites de gala" (Labbé, t. IX, 1939: 58). ${ }^{15}$ Entre as personalidades ligadas ao cinema nazista, Leni Riefensthal esteve presente em uma dessas soirées, apresentando seu filme sobre as Olimpíadas no Pavilhão Alemão (Sem autor [2], 1937: 4).

Além dessas exibições, diversos equipamentos cinematográficos, demonstrativos da pujança da indústria alemã, foram expostos nas seções alemãs do Pavilhão Internacional. ${ }^{16}$ Projeções de filmes alemães ocorriam também no Palais du Trocadéro e no Musée de l'Art Moderne.

Outro pavilhão que deve ser trazido a esta discussão é o da Espanha. Em meio à Guerra Civil, a concepção de seu projeto arquitetônico e sua ocupação, tanto pelos quadros e estátuas quanto pelos filmes e festas populares, foi também pensada como afirmação da resistência popular ao franquismo, apoiado, como se sabe, por Hitler. Como diz Martha Thome, o pavilhão é um exemplo de uma "démarche arquitetural fortemente influenciada por considerações externas" (Paris 1937, 1987: 146). Ao contrário dos outros pavilhões, não se tratava propriamente de preencher o espaço com produtos e materiais para demonstrar a sintonia do país com o desenvolvimento capitalista. O ideal que deveria ser materializado era o enfrentado então pelo povo espanhol, como nos diz o comissário geral do pavilhão, José Gaos:

lutar e morrer por um mundo e uma civilização conforme o ideal moderno (...) de livre e pacífica autodeterminação dos povos 
no seio do respeito mútuo e da colaboração de todos à história da cultura humana (Gaos, 1937:20). ${ }^{17}$

Inaugurado dois meses e meio depois do bombardeio de Guernica, em 12 de julho de 1937, suas paredes receberam Guernica, de Picasso, obra-monumento que sintetiza no campo visual a dimensão de 'confronto' percebida entre os diferentes pavilhões da Exposição. Como nos demais espaços expositivos, seu lugar foi definido pelo arquiteto do pavilhão, José-Luis Sert (Martín, 1982: 121). ${ }^{18}$ Em frente à obra de Picasso estava a obra de outro moderno, La Fontaine de Mercure, de Alexander Calder. Tivemos também Juan Miró, com Paysan catalan en révolte, os escultores Alberto Sanchez, com L'Espagne a un chemin et au bout son étoile, de 12 metros de altura, logo à entrada do pavilhão, e Gonzalez, com $M a$ ternité. ${ }^{19}$

Como dissemos, havia também projeção de filmes. Sessões semanais eram dedicadas a mostrar documentários. O único levantamento de que temos notícia é o de Fernando Martín, a partir do jornal do Partido Comunista Francês, o L'Humanité, que registrou as atividades de alguns pavilhões. Eis a sua filmografia: El Escorial y Felipe II (1931) e Almadrabas (1934), de Velo e Mantilla; La ruta de d. Quijote (1935), de Ramón Biadiu; Guadalquivir (1935), de Heinrich Gaertner; Reforma Agraria, Madrid e España 36, este último de Mantilla, subvencionados pela subsecretaria de Propaganda do Ministério do Estado; El Tribunal de las Aguas (1937), de Angel Villatoro, produzido por Film Popular. Três filmes não foram identificados, a saber, Guerra en los campos, Sinfonia Vasca, e Fuan Simon (Martín, 1982: 198-201).

Não se sabe ao certo se os seguintes filmes foram projetados: Tierra española (1937), de Joris Ivens, e Madrid 36 o España Leal en Armas (1936), de Luis Buñuel e Jean-Pale Chanois. Buñuel, que foi o montador desse documentário, se encontrava em Paris desde setembro de 1936, quando foi nomeado adido cultural da embaixada da Espanha na capital francesa (Martín, 1982: 205). Sua função, como o próprio cineasta diz, "era agrupar todos os filmes de propaganda republicana rodados na Espanha" (Buñuel, 2009: 226). Certamente, deve ter tido participação ativa na programação de filmes no pavilhão espanhol.

Buñuel aproveitou o momento para sonorizar, no final de 1936, Las Hurdes (1933), também conhecido como Terre sans pain, documentário de sua autoria que foi exibido na capital francesa em fevereiro do ano seguinte. $O$ filme participou da Exposição e recebeu a Medalha de Prata pela representação espanhola na classe 6 (Cerf, 1937: 68). ${ }^{20}$

Sua escolha pela delegação espanhola para concorrer a um dos prêmios da Exposição é emblemática por vários motivos. Em primeiro lugar, pelo fato de que o documentário, que trata de uma das regiões mais pobres da Espanha, foi primei- 
ramente rejeitado pelos republicanos. Já em 1937, Las Hurdes foi transformado pelo próprio governo republicano em peça de denúncia de um atraso pelo qual também eram responsáveis. Essa reorientação na leitura do filme foi realizada pelo próprio Buñuel, que acrescentou naquele ano o seguinte comentário ao final do filme: "Com a ajuda dos antifascistas do mundo inteiro, a calma, o trabalho e a felicidade tomarão o lugar da guerra civil e farão desaparecer para sempre os focos de miséria que mostramos neste filme" (L'Avant-Scène du Cinéma, 1964: 62). O diretor procurou resolver as ambiguidades ${ }^{21}$ de Las Hurdes com uma declaração que reorientava a leitura de sua obra para o contexto imediato da Exposição.

Nessa disputa, o reconhecimento por parte da organização não deixava de ser também uma manifestação de apoio à resistência antifascista, que apontava o nazifascismo como o inimigo a quem cabiam todas as culpas pela situação histórica da Espanha. A cobertura dada pelo jornal do Partido Comunista Francês às atividades cinematográficas do pavilhão espanhol, além da própria participação de Picasso com Guernica e de Buñuel com Las Hurdes, demonstravam simbolicamente a tentativa da arte de intervir em um campo já minado por um confronto visível nos pavilhões dispostos ao redor da Torre Eiffel.

Como em toda exposição, a reunião de diferentes países, abrigados em pavilhões cuja arquitetura expressava tanto o avanço quanto a tradição nacional, permitia ao visitante a experiência visual de um mundo em miniatura. $O$ cinema potencializava essa sensação, valorizando os aspectos socioculturais de suas nações. Reforçava e intensificava assim a viagem vivenciada pelos fair goers que percorriam os diferentes espaços da feira naqueles meses de 1937.

Nessa viagem pelos quatro cantos do mundo espalhados ao longo do rio Sena, o cinema ocupou lugar de destaque no confronto que antecipou a guerra e o horror que estavam por vir.

Notas

1. Lemoine considera em sua conta apenas as exposições de $1855,1867,1878,1889$, 1900 e 1925. Para ele, a Exposition Coloniale de 1931 "tinha um caráter muito específico" para ser comparada à de 1937.

2. Sobre o contexto político da época e o lugar do regionalismo nesse quadro, ver Madeleine Rebérioux (1987: 26-29). Pascal
Ory detalha o programa da Frente Popular para o evento (1987: 30-35). A respeito do regionalismo, ver também Edmond Labbé (t. VIII, 1938).

3. O volume do relatório oficial dedicado aos resultados da exposição foi publicado apenas em 1940. O atraso, geralmente comum em relatórios desse tipo, deveu-se 
à eclosão da guerra. Nesse sentido, o balanço é amargo: "podia-se prever a catástrofe que se abateria sobre o mundo?" (Labbé, t. X, 1940: VII).

4. Sobre o trabalho coletivo envolvido na confecção de uma pintura mural, ver o depoimento de Robert Delaunay em Palais de l'Air et des Chemins de Fer, Robert Delaunay (apud 1937, Exposition Internationale des Arts et des Techniques, 1979: 15).

5. Lemoine faz uma discussão aprofundada sobre os estilos arquitetônicos presentes nos pavilhões e demais edificações da exposição. Jean-Louis Cohen trata do pavilhão soviético (Paris 1937, 1987: 183-189).

6. Sobre o pavilhão alemão ver também Labbé (t. IX, 1939: 11-64).

7. Para uma discussão aprofundada sobre o lugar da luz na arquitetura nazista, ver também Rosi Huhn (Paris 1937, 1987: 397).

8. O cinema também participa de outros grupos, como o IV, 'Diffusion artistique et technique' (Labbé, 1938, t. I: 302). Na Comissão de Cinema o presidente de honra foi Louis Lumière e entre seus membros tivemos René Clair, Germaine Dulac, Léon Gaumont, Jean Painlevé, Charles Pathé e Émile Vuillermoz. Quase todas as associações de classe e os sindicatos ligados ao setor foram representados nesta comissão (Labbé, t. I, 1938: 435, 438-439). O relatório de Georges Cerf (1937: 10-12) acrescenta nomes como, por exemplo, Abel Gance e Jean Renoir.

9. Além de Lumière, que tinha um busto no Pavilhão Photo-Ciné-Son, outro patriarca do cinema francês foi celebrado. Georges Méliès, "sem nenhuma dúvida, o primeiro metteur en scène do mundo", é homenageado com um sessão dedicada a ele no Ciné 37 (Sem autor [1], 1937: 7).

10. Essa denominação se deve ao fato de que nem todos os filmes produzidos naquele ano, inclusive "alguns dos filmes mais significativos da recente produção francesa", como afirma René Jeanne, foram inscritos no concurso (Georges Cerf, 1937: 48). O vencedor desse concurso foi La Mort du Cygne (1937), de JeanBenoit Lévy e Marie Epstein. Para Jeanne, ao conferir esse prêmio, os jurados quiseram mostrar que "tinham assimilado e apreciado as preocupações morais e artísticas" dos envolvidos com a realização do filme (Georges Cerf, 1937: 51).

11. Mais adiante, René Jeanne afirma terem sido os produtores desses filmes os responsáveis pela sua retirada do concurso, cientes que estariam do fato de não atenderem ao prescrito no regulamento (Georges Cerf, 1937: 50).

12. A título de exemplo, no relatório oficial da Exposição de 1925, The Cheat é citada como uma das três obras "admiráveis" que chegaram dos EUA em 1915-1916 (as outras são Work (1915), de Charles Chaplin, e The Aryan (1916), produzido por Thomas Ince) (France. Ministère du Commerce, de l'Industrie, des Postes et des Télégraphes, 1929: 68).

13. Sobre a decoração do pavilhão e seus stands ver Edmond Labbé (t. V, 1939: 84 e ss. e 248 e ss).

14. Sobre a programação de cinema dos pavilhões do Japão, Polônia e Portugal ver Edmond Labbé (t. X, 1940: 25, 111, 133).

15. O relatório oficial destaca a exibição de Triunfo da Vontade, o filme em cores Allemagne "e relatório filmado sobre a criação de um empresa de cinema nas Olímpiadas de Berlim 1936" (Edmond Labbé, t. IX, 1939: 62). A relação completa dos filmes se encontra nas p. 59-62.

16. Em detalhe, a relação se encontra em Edmond Labbé (t. IX, 1939: 35-36).

17. Para um crítico da época, trata-se da exposição da "dor espanhola" (A. Ozenfant, apud 1937, Exposition Internationale des Arts et des Techniques, 1979: 18). 
18. Fernando Martín historia a encomenda do quadro pelo governo republicano (1982: 121 e ss.).

19. Para uma descrição do pavilhão espanhol ver Edmond Labbé (t. IX, 1939: 170-176).

\section{Referências bibliográficas}

BRÉON, E. L'Exposition des arts décoratifs. In: Vários autores. Création et vie artistique: au temps de l'exposition de 1925. [Paris]: Centre National de Documentation Pédagogique, 2006.

BUÑUEL, L. Meu último suspiro. São Paulo: Cosac Naify, 2009.

CERF, G. Photo et cinéma à l'exposition de 1937: classe VI, manifestations cinématographiques; classe XIV, photographie et cinématographie. [Paris]: [s.n.], [1937].

CHANDLER, A. Paris 1937. Exposition Internationale des Arts et Techniques dans la Vie Moderne. In: FINDLING, J. e PELLE K. (eds.). Historical Dictionary of World's Fair and Expositions, 1851-1988. NY: Greenwood Press, 1990.

FRANCE. Ministère du Commerce, de l'Industrie, des Postes et des Télégraphes. Exposition Internationale des Arts Décoratifs et Industriels Modernes, Paris, 1925. Rapport général. Section Artistique et Technique. Volume $X$. Théâtre, Photographie et Cinématographie. Paris : Librairie Larousse, 1929.

GAOS, J. Espagne. Paris 1937: Revue de l'Exposition: arts et techniques, n. 15, septembre-octobre 1937, p. 20.

LABBÉ, E. (rapporteur). Ministère du Commerce et de l'Industrie. Exposition Internationale des Arts et Techniques. Rapport
20. Não há no levantamento de Fernando Martín qualquer referência à exibição de Las Hurdes na Exposição de 1937.

21. James Lastra (1999: 51-68) trata de forma brilhante das ambiguidades deste filme.

Général. Tome I. Paris, Imprimerie Nationale, 1938.

La Section Française: les participations officielles. Rapport Général. Tome IV. Paris: Imprimerie Nationale, 1939.

-La Section Française: les groupes et les classes. Groupes I a V. Rapport Général. Tome $V$. Paris, Imprimerie Nationale, 1939.

La Section Française: les participations régionales. Rapport Général. Tome VIII. Paris, Imprimerie Nationale, 1938.

- Les Sections Étrangères ( ${ }^{\text {ère }}$ Partie). Rapport Général. Tome IX. Paris, Imprimerie Nationale, 1939.

- Les Sections Étrangères (2 ${ }^{\text {ème }}$ Partie). Rapport Général. Tome X. Paris, Imprimerie Nationale, 1940

- La vie et les résultats de l'exposition. Rapport Général. Tome XI. Paris, Imprimerie Nationale, 1940.

LAMBERT, J. Les sections étrangères. In: Exposition internationale de Paris 1937: arts et techniques. Paris, LIllustration, 1937, sem indicação de página.

LASTRA, J. Why is this absurd picture here? Ethnology/Equivocation/Buñuel. October, vol. 89, Summer 1999, p. 51-68. 
LEMOINE, B. Préface; REBÉRIOUX, $M$. L'Exposition de 1937 et le contexte politique des années trente; ORY, P. Le front populaire; BARTEZKO, D. Allemagne. Albert Speer; THOME, M. Espagne. JoseLuis Sert et Luis Lacasa; COHEN, J-L. U.R.S.S. Boris Iofan; LEMOINE, B. e RIVOIRARD, P. Electricité et lumière. Robert Mallet-Stevens, Georges-H. Pingusson; PEER, S. Photo-cine-phono. Saint-Maurice et Lemaire; CHAVANNE, B. e GUTTINGER, C. La peinture décorative; HUHN, R. Art et technique: la lumière. In: Paris 1937: cinquantenaire de l'Exposition Internationale des Arts et des Techniques dans la Vie Moderne [Exposition, Musée d'Art Moderne de la Ville de Paris, 13 mai-30 août 1987]. Paris: Institut Français d'Architecture: Paris-Musées, 1987, p. 10-23; 26-29; 30-35; 134-139; 146-151; 183-189; 221-225; 234-236; 364-391; 392-403.

MANCINI, M. Pictures at an Exposition. Film Comment, v. 19, n. 1, jan/feb 1983.

MARTÍN, F. El Pabellón Español en la Exposición Universal de Paris en 1937. Sevilla: Universidad de Sevilla, 1982.

MORETTIN, E. As exposições universais e o cinema: história e cultura. Revista Brasi- leira de História. vol. 31, n. 61, 2011, p. 231249.

1937, Exposition Internationale des Arts et des Techniques. Paris: Centre Georges Pompidou, Musée National d'Art Moderne, 1979.

RENOIR, J. L'Exposition de la Liberté. Ce Soir, 22 juillet 1937 (Archive Nationale, Fonds Publics Postérieures à 1789, Série Versements des Ministères et des Administrations qui en dépendent, sub-série Commerce et Industrie, F12 12130).

Sem autor [1]. Une manifestation au Ciné 37 en l'honneur de Georges Méliès. Programme Quotidien Officiel de l'Exposition Internationale des Arts et Techniques, n. 115, 5 octobre 1937, p. 7.

Sem autor [2]. La Star Leni Riefenstahl a visité l'Exposition. Programme Quotidien Officiel de l'Exposition Internationale des Arts et Techniques, n. 21, 3 juillet 1937, p. 4

Las Hurdes, de Luis Buñuel. L'Avant-Scène du Cinéma, n. 36, 1964.

XAVIER, I. De monumentos e alegorias políticas: a Babilônia de Griffith e a dos Taviani. Estudos de Cinema, n. 2, 1999, p. 125-152.

\section{Resumo}

$\mathrm{O}$ artigo examina a presença do cinema na Exposition Internationale des Arts et des Techniques (Paris, 1937), discutindo as imbricações entre a cultura da modernidade e as contendas políticas e ideológicas no período entre guerras. Marcada pelo confronto arquitetônico, expressão simbólica de um conflito iminente, a exposição tem no cinema um participante ativo do embate. Com estatuto inédito, considerado expressão do pensamento e "potência ditatorial da época", ele é utilizado para marcar a perspectiva de cada país a respeito do seu lugar no mundo.

Palavras-chave: cinema e história; história do cinema; exposições universais. 


\begin{abstract}
The article examines the presence of cinema in the Exposition Internationale des Arts et des Techniques (Paris, 1937), through the discussion of the inter-relationship between modern culture and political-ideological battles in the in-between wars period. Marked by architectural confront, symbolic expression of an imminent conflict, the exposition has also in the cinema an active participant of this clash. With an original statute, considered the expression of thinking and "dictatorial potency of the epoch", cinema is used to highlight the perspective of each country in regard to its place in the world.
\end{abstract}

Key words: film and history; film history; world fairs.

\title{
Résumé
}

L'article examine la présence du cinéma dans l'Exposition Internationale des Arts et des Techniques (Paris, 1937), en analysant l'interrelation entre la culture moderne et les conflits politico-idéologiques des années entre les deux guerres. Marquée par la confrontation architecturale, expression symbolique d'un conflit imminent, l'exposition a dans le cinéma un participant actif de ce choc. Détenteur d'un statut originel, considéré l'expression de la pensée et «puissance dictatoriale de l'époque“, le cinéma est utilisé pour mettre en évidence le point de vue de chaque pays en ce qui concerne sa place dans le monde.

Mots-clés: cinéma et histoire; histoire du cinéma; expositions universelles. 